\title{
THE NEEDS OF PERSONS WITH CHRONIC HEALTH CONDITIONS TO MAINTAIN OR RETURN TO WORK 30 YEARS AFTER TRANSFORMATION FROM SOCIALISM INTO CAPITALISM - A PRELIMINARY REPORT FROM THE POLISH PART OF THE PATHWAYS PROJECT
}

\author{
ALEKSANDER GAŁAŚ ${ }^{1}$, ALEKSANDRA PIŁAT ${ }^{1}$, BEATA TOBIASZ-ADAMCZYK ${ }^{1}$, and MATILDE LEONARDI ${ }^{2}$ \\ ${ }^{1}$ Jagiellonian University Medical College, Kraków, Poland \\ Chair of Epidemiology and Preventive Medicine \\ ${ }^{2}$ Foundation IRCCS Neurological Institute Carlo Besta, Milan, Italy
}

\begin{abstract}
Objectives: An increased burden of chronic diseases in the working age population is observed across high income countries. Persons with chronic diseases (PwCDs) are less likely to maintain or return to work due to several constraints they experience. The purpose of the study was to assess the preferences and needs of PwCDs regarding 6 areas of flexibility at the workplace. It was assessed whether there were any personal characteristics associated with higher or lower expectations and needs. Material and Methods: This was a part of a large multicenter international project, i.e., the PArticipation To Healthy Workplaces And inclusive Strategies in the Work Sector (PATHWAYS) project, aimed to contribute to the development of innovative approaches to promote professional integration and reintegration of PwCDs into the work sector. In Poland, 59 respondents diagnosed with different chronic diseases were identified through advocacy groups. An on-line survey was conducted to collect information on their needs and expectations. A cluster analysis was performed to reveal some expectation types which differentiated individuals across 6 analyzed domains, along with a multivariable logistic regression to identify some characteristics associated with a special expectation type. Results: Workplace facilitator items were generally scored as needed ("rather conductive" and "very conductive" groups identified). The factors positively associated with higher needs in this domain were education, and a hindering type of the disease. Unrestricted working hours were very conductive or indifferent, and were positively associated with education. Legal solutions were more conductive for older people. Medical support, access to training, and supervisors' knowledge were needed in general, with no associations with the personal characteristics identified. Conclusions: Persons with chronic diseases report several facilitators which are needed for them to maintain or return to work, but they are not satisfied with the existing economy in Poland. These needs should be taken into consideration in the effective policy development. Int J Occup Med Environ Health. 2020;33(4):427-44
\end{abstract}

Key words:

disability, workplace, needs assessment, flexibility, chronic conditions, labor force

Funding: this research was supported by the European Union's Health Program (2014-2020) (grant No. 663474, the project entitled "PArticipation To Healthy Workplaces And inclusive Strategies in the Work Sector (PATHWAYS)," project manager: Matilde Leonardi, Ph.D.) and by the Polish Ministry of Science and Higher Education (grant No. 3649/HP3/16/2017/2 entitled "The Financial Recourses for Research in years 2016-2018 Granted for the Realization of International co-financed Project," project manager: Prof. Beata Tobiasz-Adamczyk).

Received: April 20, 2018. Accepted: February 13, 2020

Corresponding author: Aleksander Gałaś, Jagiellonian University Medical College, Chair of Epidemiology and Preventive Medicine, Kopernika 7, $31-034$ Kraków, Poland (e-mail: aleksander.galas@uj.edu.pl). 


\section{INTRODUCTION}

The modern world is characterized by increasing life expectancy and an accompanying increased risk of a chronic disease and disability. The development of a chronic medical condition is observed relatively early in one's lifetime among a significant part of adult populations, as it starts in one's fifties or even forties. As revealed by the research, people aged 45-64 suffer from 1.18 chronic disease on average; by the age of 50 , every second person has at least 1 morbidity, and by the age of 65 , most adults are multimorbid [1]. These groups are persons of working age, and the diagnosis of a chronic disease has a remarkable impact on their personal and professional life. The presence of a chronic disease is linked with different levels of disability and, consequently, affects employment prospects and significantly increases the intention to retire early [2]. An analysis of the Survey of Health, Ageing and Retirement in Europe (SHARE) data has shown that people with hypertension are $6 \%$ less likely to be employed, as compared to those without hypertension, while diabetes and heart disease decrease the likelihood of being employed by about $15 \%$, and stroke by $22 \%$ [2].

The outflow of persons with chronic diseases (PwCDs) from the labor market has a remarkable impact on national economy causing productivity losses (due to early retirement and absenteeism), and an increased use of health care resources. This unfavorable tendency is observed in the majority of high income European countries, including Poland.

In the previous decade, the number of chronically ill adults (aged $\geq 15$ ) in Poland increased from about $26 \%$ in 2006 to $34 \%$ in 2016 [3]. This corresponds to about 20\% of the population aged 25-44 reporting a chronic disease, and this share increases to $42 \%$ in the $45-59$ age category, and to $63 \%$ in the 60-69 age category [3]. Overall, about $17.7 \%$ of the adult population in Poland report limitations in their daily living activities, lasting $\geq 6$ months. According to the latest available records published by the Central
Statistical Office of Poland [4], 11.9\% of the economically inactive people of working age are non-employed and do not seek a job due to an illness and disability. This corresponds to 1278000 potential workers aged 25-64 who are staying outside the labor market, and nearly $80 \%$ of them are persons who were previously in employment [4].

There are several causes which make PwCDs to stay outside the labor market, including system regulations and service providers, employers, and workplace features. After an acute disease period, disability management plays a key role in minimizing the impact of the disease and impairment on one's personal life and ability to return to work. The development of easily accessible, affordable and effective disability management programs, which facilitate early intervention and keep workers engaged in the workplace, is among crucial initiatives that should be organized at the global and local levels [5]. The responsibility of employers being the main contributors in the process includes their willingness to hire PwCDs, and to provide both workplace and social standards which facilitate effective, safe and healthy work. The most important stakeholders, however, are PwCDs themselves.

There are several personal determinants which influence one's decision about staying outside or returning to workforce. These may be categorized into economic and psycho-social ones. The economic drive is closely related to the need to cover household and daily living expenses, and the costs of leisure time activities, and to buy specific goods. The psycho-social category is a subject of much broader discussions as a determinant of taking up a job. Work gives independence and a better control of one's life; it is also a source of satisfaction, empowerment, commitment, self-esteem, and self-realization. Working people may learn new things, get more skills, and make new friends or maintain friendships with their co-workers, which is the source of support [6,7]. Therefore, among the most important determinants which influence PwCDs' participation in the labor market is an individual percep- 
tion of work flexibility which enables PwCDs to retain their job or return to work after treatment of acute disease episodes.

Numerous research results have shown that flexible working conditions provided by the employer are associated with increased job satisfaction, better engagement, and higher motivation [8,9]. It was also shown that better working conditions are linked with better work-family balance [10]. They also lead to reduced stress and burnout [11].

The needs of people with different limitations, handicaps or disabilities are also shaped by the abilities determined by the labor market and employers' goals. It has meaningfully changed after the economic transition launched in 1989-1991 in Poland. These changes have led to full liberalization and privatization, and a rapid growth of small private businesses and large companies which aimed on assets. Before the transition period, but after Second World War, Poland intensively developed its social security policy to help disabled persons. There were occupational rehabilitation rules developed by Hulek [12] and Kirenko [13], which stated that each person with disability, despite the experienced health deterioration and limitations, should keep some functions and abilities, and have some compensative and developmental possibilities, which would enable him or her to develop new professional skills. Moreover, Hulek and Kirenko stated that there was no job which required from the disabled person to use all the functions and capabilities of the human body. This was the basis for developing a Polish model of occupational rehabilitation which tried to include disabled persons in the country's economic goals.

Among different activities, rapid development of disabled workers co-operatives took place. The mission of these co-operatives was to conduct economic activities associated with physical, social, and educational and cultural rehabilitation. There were 2 types of work activities of co-operative members. Some of them were coming to the workplace, but those with severe impairments were working from their homes, operating within the cottage industry. The second group frequently worked with the help of their family or friends. In the 1970s, more than onethird of the hired disabled persons were working this way, which represented approx. 40000 workers [14]. The basis for disabled workers co-operatives was also complex rehabilitation which included medical, rehabilitative, and social services. There were rehabilitative clinics, hired physicians, nurses, physiotherapists, massage therapists and social workers who concentrated on functional improvements, on the prevention of comorbidities, and on treatment of the underlying disease [15]. In 1967, next to disabled workers co-operatives, a regulation was adopted by the Council of Ministers in Poland for the planned employment of disabled persons, which obliged workshops to set up workplaces suitable for disabled persons, and to adapt some workplaces. Additionally, it was required that occupational health care should provide special rehabilitative and social services to people with impairments [16]. During and after the transition from socialism to capitalism, the situation of people with work performance limitations in Poland changed remarkably. The main economic focus on assets led to a decreased support for disabled persons on the labor market. Additionally, in 1990 the decision by the Second Congress of Polish Co-Operatives to shutdown collective clubs led to the elimination of disabled workers co-operations [17]. Moreover, the Polish parliament in 1990 passed a resolution requiring all collective organizations to be closed down, which led to the elimination of the Central Union of Disabled Workers Co-Operatives, of the Central Union of Blind Workers Co-Operatives, and of Regional and Provincial Unions of Disabled Workers Co-Operatives [18]. It was believed that an open market would solve the problems of disabled persons. However, the business model so adopted led to a decrease in rehabilitation services. Even after the transition, when the new rules were set up, the number of sheltered workshops decreased in 1999-2015 by two-thirds, from 3736 to 1179 , 
and the number of employed disabled persons decreased from 218130 in 1999 to 128800 in 2015 [19].

Rapid, or even revolutionary, changes which also involved the Polish labor market provided a unique opportunity to investigate the impact of changes and the current situation of PwCDs. Thus, the purpose of this study was to assess the preferences and needs of PwCDs in Poland, the country being about 25 years after economic transition. The needs were investigated considering 6 areas of flexibility at the workplace, including workplace environment, working hours flexibility and the level of supervisor control, legal solutions, medical circumstances, access to training and counseling, and co-workers and supervisors' knowledge of the consequences of chronic conditions. It was assessed whether there were groups of PwCDs with higher or lower expectations in the areas under consideration, and whether there were any personal characteristics associated with specific needs and expectations.

\section{MATERIAL AND METHODS}

This part of the study formed part of a large multicenter international project, i.e., the PArticipation To Healthy Workplaces And inclusive Strategies in the Work Sector (PATHWAYS) project, aimed to contribute to the development of innovative approaches to promote professional integration and reintegration of PwCDs into the work sector. The PATHWAYS project details have been described elsewhere [20]. In brief, the project gathered health professionals representing different disciplines (academics, non-governmental organizations working for the integration of persons with health-related problems into the work sector, educational bodies, national health institutes, and social-service and governmental institutions aiming at and providing patient-centered services) to identify and analyze the existing policies, systems and politics to (re)integrate PwCDs into the open labor market, and to identify gaps between their needs and expectations, and the available and accessible solutions provided by the work sector across different European countries. The barriers existing in the Polish system were described and discussed in a manuscript by Piłat et al. [21].

The PATHWAYS project included also detailed investigations performed among PwCDs. The respondents involved in the Polish part of the project were patients with chronic conditions identified and contacted through advocacy groups. There were individuals identified as having one of the following health outcomes: depression, migraine, diabetes, musculoskeletal disorder(s), chronic obstructive pulmonary disease, and cardiovascular disease. They were asked to provide responses in an on-line survey which was aimed at collecting information about the respondents' demographic characteristic, employment and economic status, and a questionnaire investigating their needs and expectations. The questions gathered (using a 5-point Likert scale from 1 - "very inimical," through 2 - "inimical," 3 - "neither conducive nor inimical," 4 "conducive," to 5 - "very conducive") patients' opinions across 6 domains, as:

- workplace facilitators,

- unrestricted working hours, and less control and a lowstress job,

- legal solutions protecting PwCDs,

- medical support for PwCDs,

- access to training and counseling,

- co-workers and supervisors' knowledge of the consequences of chronic conditions.

The study group included 59 individuals with the mean age of 40 . There were $41(69.5 \%)$ women and $18(30.5 \%)$ men involved, and $88 \%$ of the respondents had high school or university education. The majority of the respondents were non-managers (approximately 70\%). There were 36 (61.0\%) PwCDs employed during the survey. The respondents represented different types of diseases which caused work performance limitations, and 20 were classified as less hindering, 28 (47.5\%) as hindering, and 11 as very hindering. There were no statistically significant differences 
Table 1. Characteristics of the Polish part of the PATHWAYS project representing persons with chronic diseases (PwCDs) in the Małopolska region, data collection in 2016-2017

\begin{tabular}{|c|c|c|c|c|}
\hline \multirow{2}{*}{ Variable } & \multicolumn{3}{|c|}{$\begin{array}{l}\text { Participants } \\
(\mathrm{N}=59)\end{array}$} & \multirow{2}{*}{$\mathrm{p}$} \\
\hline & total & $\begin{array}{c}\text { employed } \\
(\mathrm{N}=36)\end{array}$ & $\begin{array}{l}\text { non-employed } \\
\qquad(\mathrm{N}=23)\end{array}$ & \\
\hline Gender $[\mathrm{n}(\%)]$ & & & & $0.580^{\mathrm{a}}$ \\
\hline men & $18(30.5)$ & $12(33.3)$ & $6(26.1)$ & \\
\hline women & $41(69.5)$ & $24(66.7)$ & $17(73.9)$ & \\
\hline Age [years] $(\mathrm{M} \pm \mathrm{SD})$ & $39.5 \pm 11.7$ & $40.5 \pm 11.0$ & $37.9 \pm 12.8$ & $0.559^{\mathrm{b}}$ \\
\hline Education $[\mathrm{n}(\%)]$ & & & & $0.999^{c}$ \\
\hline middle school or vocational & $7(11.9)$ & $4(11.1)$ & $3(13.0)$ & \\
\hline high school or university & $52(88.1)$ & $32(88.9)$ & $20(87.0)$ & \\
\hline Occupational classification [n (\%)] & & & & $0.999^{\mathrm{a}}$ \\
\hline non-managers & $41(69.5)$ & $25(69.4)$ & $16(69.6)$ & \\
\hline managers & $18(30.5)$ & $11(30.6)$ & $7(30.4)$ & \\
\hline Disease & & & & $0.501^{\mathrm{c}}$ \\
\hline less hindering & $20(33.9)$ & $13(36.1)$ & $7(30.4)$ & \\
\hline hindering & $28(47.5)$ & $18(50.0)$ & $10(43.5)$ & \\
\hline very hindering & $11(18.6)$ & $5(13.9)$ & $6(26.1)$ & \\
\hline
\end{tabular}

${ }^{a}$ Chi-square test with 1 degree of freedom; ${ }^{b}$ Mann-Whitney U test; ${ }^{c}$ Fisher's exact test.

between the employed and non-employed respondents regarding their basic characteristics (Table 1).

\section{Ethics}

The study protocol and all the procedures implemented in the research were reviewed and accepted by the Bioethics Committee of the Jagiellonian University (permission No. 122.6120.222.2016 dated June 27, 2016), and they followed the ethical standards described by the Declaration of Helsinki, revision 2013.

\section{Statistics and covariates}

Descriptive statistics, such as means and standard deviations (SDs), were used to describe the basic characteristics of the study participants. The results from the questionnaire investigating their needs and expectations were con- sidered as ratio scale variables and were described by their means and SDs using their original scoring system (i.e., from 1 - "very inimical" to 5 - "very conducive," a higher score implied a more needed, required or expected workrelated feature). The item of the company having the right to terminate the contract with a PwCD in the case of their decreased productivity was reverse re-coded $(5 \rightarrow 1 ; 4 \rightarrow 2$, $2 \rightarrow 4,1 \rightarrow 5$ ) to obtain the same results direction. To reveal the groups characterized by special preferences or needs, the k-means cluster analysis was performed. There were step strategies implemented.

Firstly, a cluster analysis with a 2-cluster solution was run in each domain of the questionnaire investigating the respondents' needs and expectations to reveal whether there are some expectation types which differentiate individuals within a domain. Secondly, the items which did not differ- 


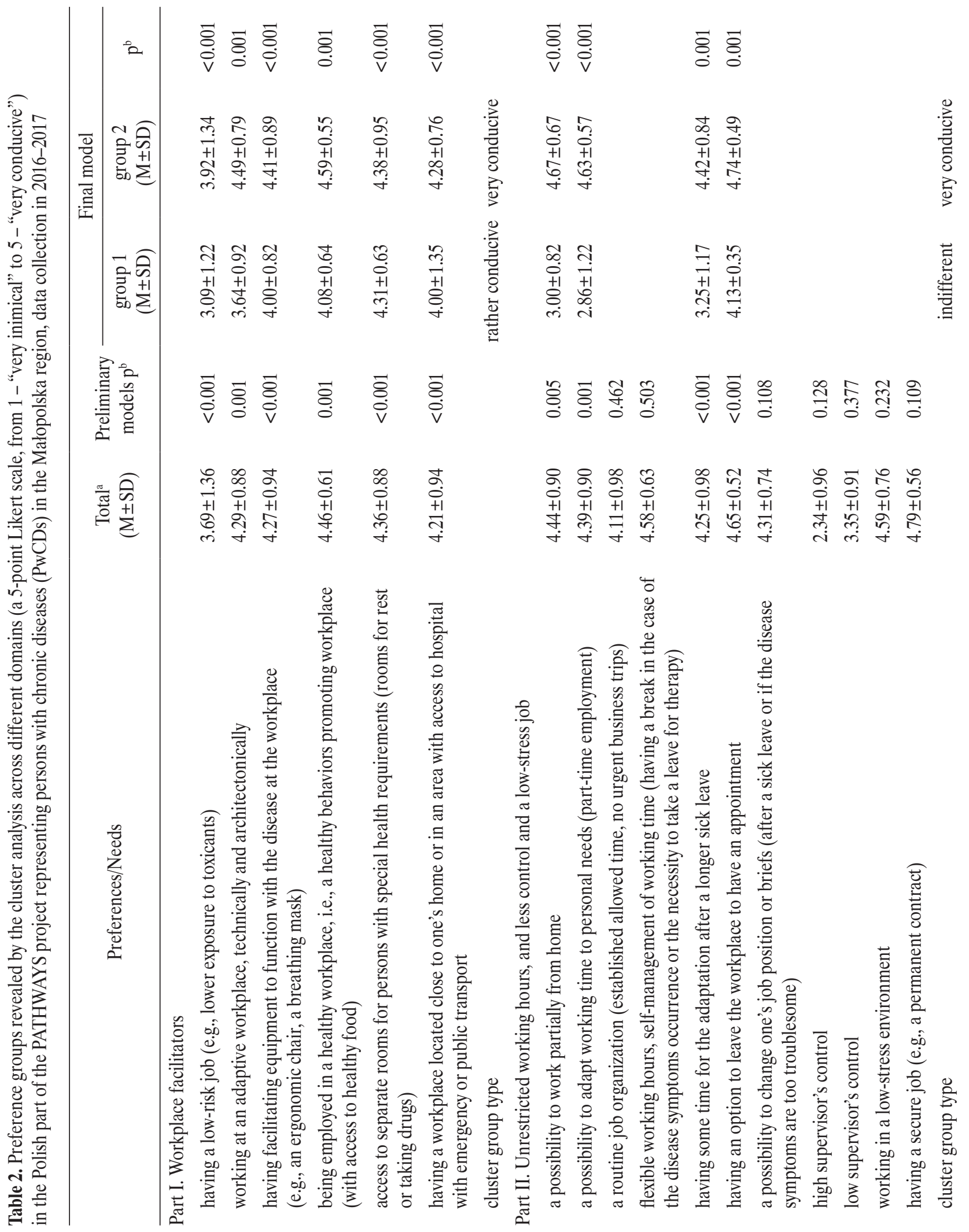




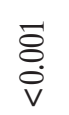

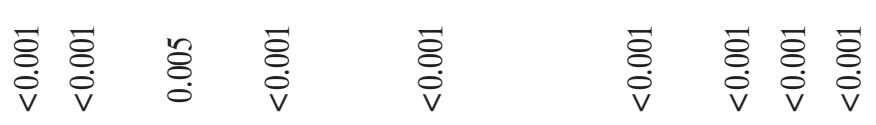

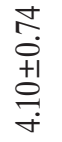

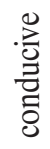

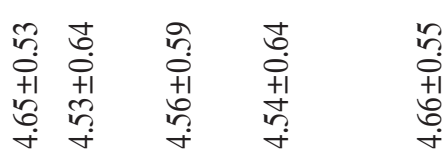

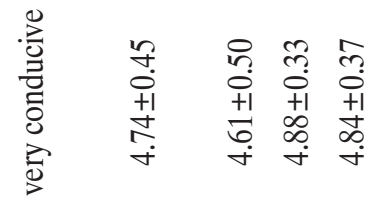

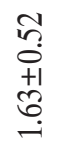

.

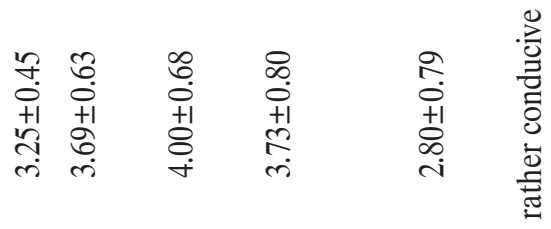

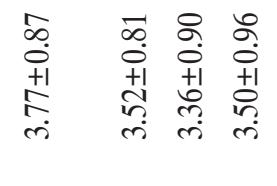

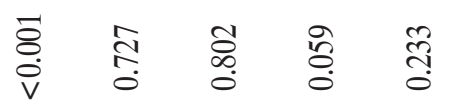

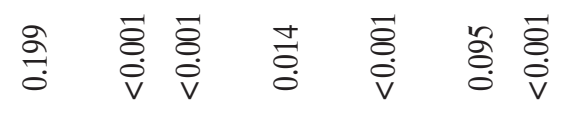

$\begin{array}{llll}\vec{\Xi} & \vec{\Xi} & \bar{\Xi} & \bar{\Xi} \\ \dot{0} & \dot{0} \\ \text { v } & 0 & 0\end{array}$

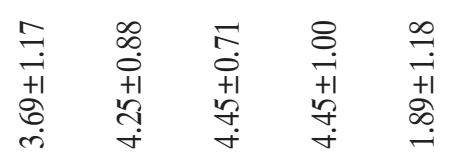

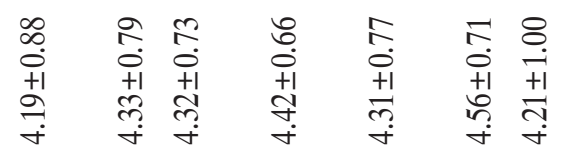

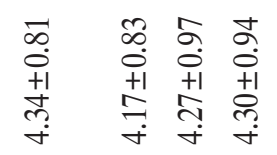

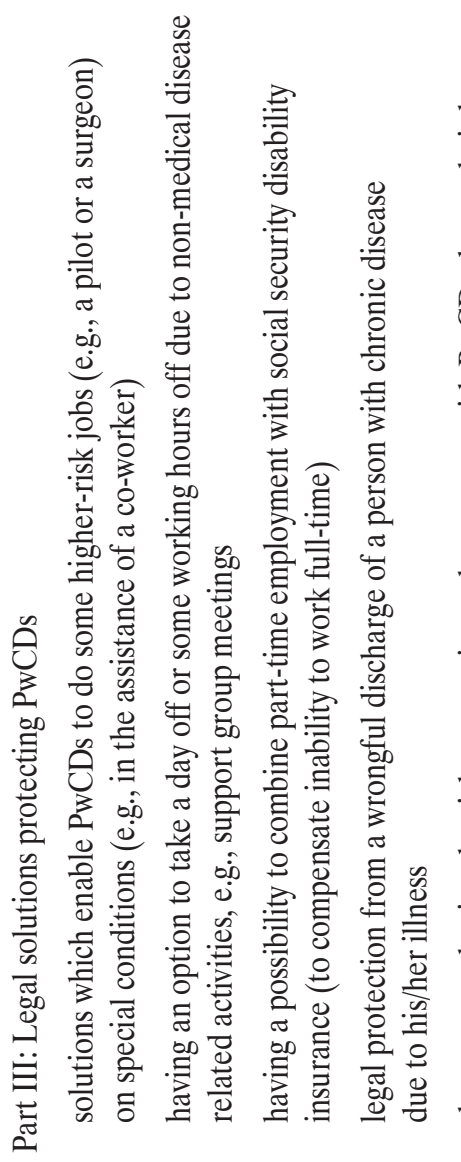

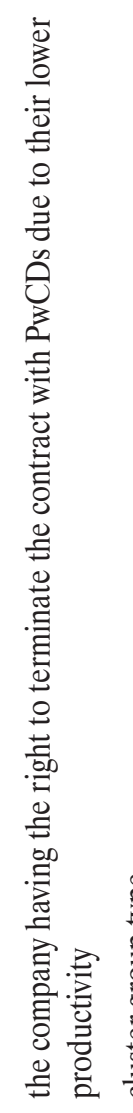

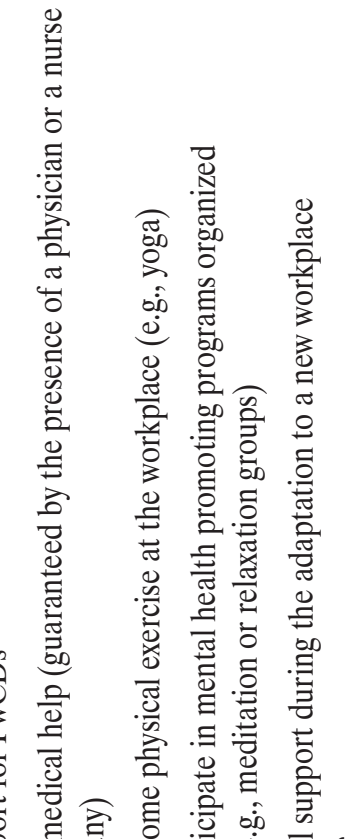

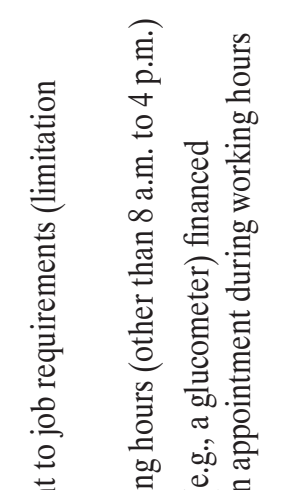

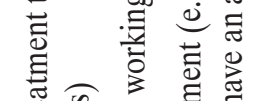

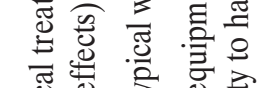

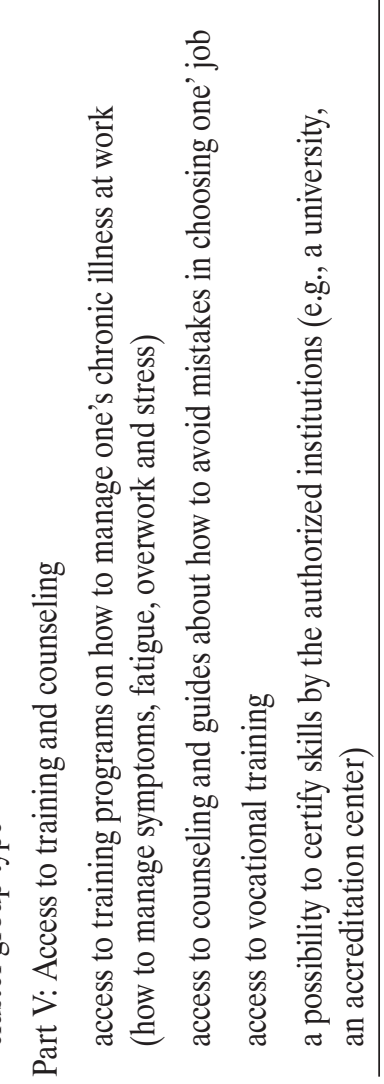




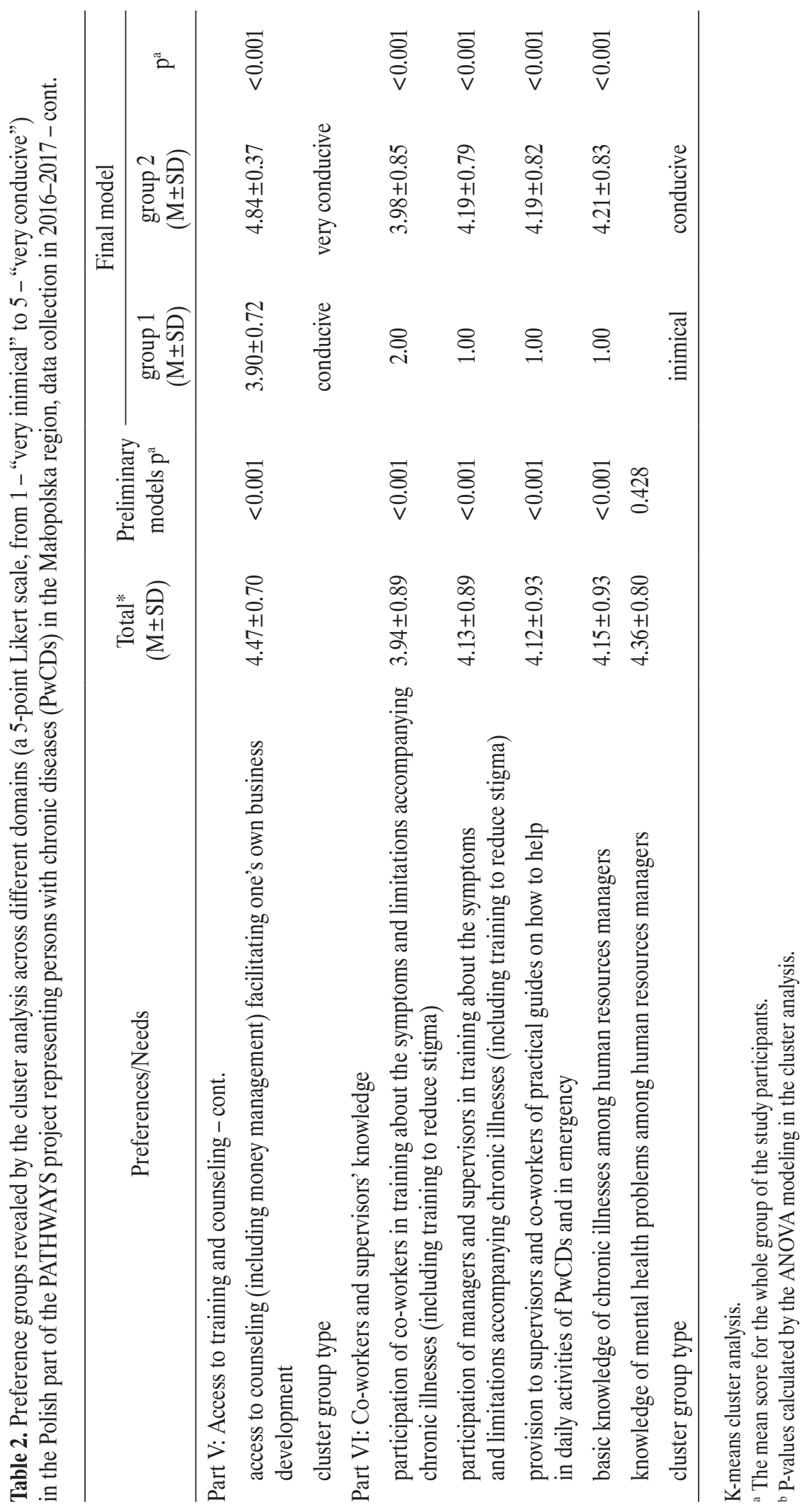


entiate the groups were removed, and the remaining ones were taken together in one 2-cluster solution analysis, and these were presented as the final model. Finally, multivariable logistic regression was used to assess whether some demographic characteristics and the type of chronic condition were associated with special expectation types across domains. Due to the small sample size, the occupation types were categorized as managers (there were managers and professionals included in this group) and non-managers (including technicians, service and sales workers, and elementary occupations). Diseases were also categorized into 3 categories, i.e.:

- very hindering, which included schizophrenia, epilepsy, tuberous sclerosis and paresis;

- hindering, which included severe arthritis, back pain, migraine, anxiety and depression;

- less hindering, which included asthma, chronic obstructive pulmonary disease, diabetes, heart disease, thyroid disease and others.

The last analysis was not performed for the "co-workers and supervisors' knowledge" domain, as the cluster analysis categorized into the "inimical" subgroup only 1 respondent.

All the analyses were performed using the IBM SPSS Statistics version 24, release 24.0.0.0, 64-bit edition. The missing values were excluded from the analyses using a pairwise strategy. The $\mathrm{p}$-value $<0.05$ was considered statistically significant.

\section{RESULTS}

Different areas of the needs and facilitators, analyzed by means of the questionnaire investigating the respondents' needs and expectations, were classified into 6 aforementioned domains. The cluster analysis used to identify groups of higher or lower priority enabled the authors to reveal 2 groups of PwCDs in the "workplace facilitators" domain. One group reported strong needs to have a safe workplace environment, architectonic workplace adapta- tions, special amenities and furnishings, and a workplace located close to their home; this group was subsequently called a "very conducive" subgroup. The other group clearly did not require such facilitators although having facilitating equipment, a healthy workplace, access to separate rooms and a workplace located close to their home was perceived as conducive; therefore, this subgroup was called "rather conducive" (Table 2).

Considering the "unrestricted working hours, and less control and a low-stress job" domain, there were 7 areas, which did not differentiate clusters. These were: routine job organization, flexible working hours, a possibility to change one' job position or briefs, working in a low-stress environment and having a secure job (these areas were scored as needed and conducive); other non-differentiating areas were a low supervisor's control assessed as neither inimical nor conducive, and a high supervisor's control which was perceived as inimical. The 2 groups created after the exclusion of non-differentiating items were: a group of PwCDs who perceived a possibility to work from home, a possibility to adapt working time to their needs, having some time for the adaptation to job requirements after a sick leave, and having an option to leave the workplace to have a medical appointment as "very conducive," and a group of PwCDs who considered these elements as "indifferent" (Table 2).

The third domain focused on legal solutions protecting PwCDs, with "solutions which enable people with a chronic disease to do some higher-risk jobs (e.g., a pilot or a surgeon) on special conditions (like in the assistance of a co-worker)" being the only factor which differentiated the PwCDs' groups. One subgroup of PwCDs clearly considered the aforementioned issue as conducive or very conducive (the "conducive" subgroup), while for the second subgroup it was inimical (the "inimical" subgroup).

In the "access to medical support" domain, there were also 2 subgroups recognized, one with very high priority on physical activity, access to mental health promoting pro- 
Table 3. Subjects' characteristics associated with the perception groups identified by their attitude to workplace facilitators, in the Polish part of the PATHWAYS project representing persons with chronic diseases (PwCDs) in the Małopolska region, data collection in 2016-2017

\begin{tabular}{|c|c|c|c|c|c|c|}
\hline \multirow[b]{2}{*}{ Variable } & \multicolumn{2}{|c|}{ Cluster group type } & \multirow[b]{2}{*}{$\mathrm{p}$} & \multirow[b]{2}{*}{$\mathrm{OR}^{1}$} & \multirow[b]{2}{*}{$95 \% \mathrm{CI}$} & \multirow[b]{2}{*}{$\mathrm{p}$} \\
\hline & $\begin{array}{l}\text { conducive } \\
(\mathrm{N}=46)\end{array}$ & $\begin{array}{l}\text { very conducive } \\
\quad(\mathrm{N}=10)\end{array}$ & & & & \\
\hline Gender $[\mathrm{n}(\%)]$ & & & $0.405^{\mathrm{a}}$ & & & \\
\hline men & $14(77.8)$ & $4(22.2)$ & & 1 (ref) & & \\
\hline women & $32(84.2)$ & $6(15.8)$ & & 0.46 & $0.06-3.37$ & 0.443 \\
\hline Age [years] $(\mathrm{M} \pm \mathrm{SD})$ & $38.2 \pm 10.4$ & $39.8 \pm 13.8$ & $0.683^{b}$ & 0.93 & $0.85-1.02$ & 0.121 \\
\hline Employment status [n (\%)] & & & $0.142^{\mathrm{a}}$ & & & \\
\hline employed & $32(88.9)$ & $4(11.1)$ & & 1 (ref) & & \\
\hline non-employed & $14(70.0)$ & $6(30.0)$ & & 0.11 & $0.01-0.91$ & 0.040 \\
\hline Occupational classification [n (\%)] & & & $0.999^{\mathrm{a}}$ & & & \\
\hline non-managers & $34(82.9)$ & $7(17.1)$ & & 1 (ref) & & \\
\hline managers & $12(80.0)$ & $3(20.0)$ & & 0.45 & $0.06-3.49$ & 0.446 \\
\hline Education [n (\%)] & & & $0.099^{\mathrm{a}}$ & & & \\
\hline middle school or vocational & $3(42.9)$ & $4(57.1)$ & & 1 (ref) & & \\
\hline high school or university & $7(14.3)$ & $42(85.7)$ & & 13.67 & $1.17-159.40$ & 0.037 \\
\hline Disease $[\mathrm{n}(\%)]$ & & & $0.086^{\mathrm{a}}$ & & & \\
\hline less hindering & $5(27.8)$ & $13(2.2)$ & & 1 (ref) & & \\
\hline hindering & $2(7.1)$ & $26(92.9)$ & & 12.94 & $1.18-141.42$ & 0.036 \\
\hline very hindering & $3(30.0)$ & $7(70.0)$ & & 1.01 & $0.12-8.53$ & 0.993 \\
\hline
\end{tabular}

Bolded are statistically significant results.

Ref - reference.

${ }^{1}$ Odds for very conducive as compared to conducive, adjusted for all other covariates listed in Table 3 .

${ }^{\mathrm{a}}$ Fisher's exact test; ${ }^{\mathrm{b}} \mathrm{t}$-test for equal variances.

grams, professional support in the workplace adaptation and pharmacological treatment adjustment, an opportunity to buy medical aids financed by the employer - and this subgroup assessed these elements as very conducive (the "very conducive" subgroup), and the second subgroup which assessed these elements as rather conducive (mean scores of 3.3-4.0) (the "rather conducive" subgroup) (Table 2).

Regarding the access to training and counseling items, almost all PwCDs perceived these as needed, but at different levels, which gave the possibility to identify those who expressed those elements as having very high priority (the "very conducive" subgroup), and those for whom these elements were also important but to a lower extent (the "conducive" subgroup) (Table 2). Finally, the "co-workers and company directors/supervisors' training" domain showed some group differences in each element considered, except the "knowledge about mental health among human resources managers." It is worth noting, however, that almost all respondents reported these aspects as needed, and in the second ("inimical") subgroup there was only 1 respondent (Table 2). In the last part, an attempt was made to find out whether there were some personal characteristics associated with 
Table 4. Subjects' characteristics associated with the perception groups identified by their attitude to unrestricted working hours, and less control and a low-stress job, in the Polish part of the PATHWAYS project representing persons with chronic diseases (PwCDs) in the Małopolska region, data collection in 2016-2017

\begin{tabular}{|c|c|c|c|c|c|c|}
\hline \multirow[b]{2}{*}{ Variable } & \multicolumn{2}{|c|}{ Cluster group type } & \multirow[b]{2}{*}{$\mathrm{p}$} & \multirow[b]{2}{*}{$\mathrm{OR}^{1}$} & \multirow[b]{2}{*}{$95 \% \mathrm{CI}$} & \multirow[b]{2}{*}{$\mathrm{p}$} \\
\hline & $\begin{array}{l}\text { indifferent } \\
(\mathrm{N}=8)\end{array}$ & $\begin{array}{l}\text { very conducive } \\
(\mathrm{N}=48)\end{array}$ & & & & \\
\hline Gender $[\mathrm{n}(\%)]$ & & & $0.254^{\mathrm{a}}$ & & & \\
\hline men & $4(22.2)$ & $14(77.8)$ & & 1 (ref) & & \\
\hline women & $4(10.5)$ & $34(89.5)$ & & 0.72 & $0.07-7.35$ & 0.781 \\
\hline Age [years] $(\mathrm{M} \pm \mathrm{SD})$ & $38.9 \pm 11.0$ & $38.4 \pm 11.1$ & $0.254^{\mathrm{b}}$ & 0.98 & $0.90-1.07$ & 0.637 \\
\hline Employment status [n (\%)] & & & $0.236^{\mathrm{a}}$ & & & \\
\hline employed & $7(19.4)$ & $29(80.6)$ & & 1 (ref) & & \\
\hline non-employed & $1(5.0)$ & $19(95.0)$ & & 20.02 & $0.72-556.22$ & 0.077 \\
\hline Occupational classification [n (\%)] & & & $0.999^{\mathrm{a}}$ & & & \\
\hline non-managers & $6(14.6)$ & $35(85.4)$ & & 1 (ref) & & \\
\hline managers & $2(13.3)$ & $13(86.7)$ & & 0.78 & $0.08-7.92$ & 0.836 \\
\hline Education [n (\%)] & & & $0.005^{\mathrm{a}}$ & & & \\
\hline middle school or vocational & $4(57.1)$ & $3(42.9)$ & & 1 (ref) & & \\
\hline high school or university & $4(8.2)$ & $45(91.8)$ & & 62.33 & 2.99-1299.90 & 0.008 \\
\hline Disease $[\mathrm{n}(\%)]$ & & & $0.677^{\mathrm{a}}$ & & & \\
\hline less hindering & $3(16.7)$ & $15(83.3)$ & & 1 (ref) & & \\
\hline hindering & $3(10.7)$ & $25(89.3)$ & & 0.68 & $0.05-9.37$ & 0.775 \\
\hline very hindering & $2(20.0)$ & $8(80.0)$ & & 0.15 & $0.01-3.23$ & 0.228 \\
\hline
\end{tabular}

${ }^{1}$ Odds for very conducive as compared to indifferent, adjusted for all other covariates listed in Table 4.

Other explanations as in Table 3.

specific levels of needs across the analyzed domains of workplace flexibility. The obtained results showed that the PwCDs who had high school or university education were more likely to assess workplace facilitators as very conducive $(\mathrm{OR}=13.7, \mathrm{p}=0.037)$, and this was independent of their gender, age, employment status, occupational classification and disease type (Table 3). The PwCDs who were categorized in terms of the possible impact of their disease as "having a hindering disease" (see the statistical analysis part), as compared to the group of "having a less hindering disease" were also more likely to score higher the possible impact of workplace facilitators $(\mathrm{OR}=12.9$, $\mathrm{p}=0.036)$. Non-employed PwCDs, however, were less likely to express a higher level of needs and/or the need of higher flexibility in this domain $(\mathrm{OR}=0.11, \mathrm{p}=0.040)$ (Table 3).

Next, high school or university education was identified as associated with a higher level of demand (the expressed need) within the "unrestricted working hours, and less control and a low-stress job" domain, which covered the areas of "a possibility to work partially at home," "to adopt working time," and "having time for adaptation and an option to leave" (OR $=62.3, \mathrm{p}=0.008)$ (Table 4). Finally, age was the feature identified as associated with the perception of "legal solutions protecting PwCD” as being conducive. After adjusting for important 
Table 5. Subjects' characteristics associated with the perception groups identified by their attitude to legal solutions protecting PwCDs, in the Polish part of the PATHWAYS project representing persons with chronic diseases (PwCDs) in the Małopolska region, data collection in 2016-2017

\begin{tabular}{|c|c|c|c|c|c|c|}
\hline \multirow[b]{2}{*}{ Variable } & \multicolumn{2}{|c|}{ Cluster group type } & \multirow[b]{2}{*}{$\mathrm{p}$} & \multirow[b]{2}{*}{$\mathrm{OR}^{1}$} & \multirow[b]{2}{*}{$95 \% \mathrm{CI}$} & \multirow[b]{2}{*}{$\mathrm{p}$} \\
\hline & $\begin{array}{l}\text { inimical } \\
(\mathrm{N}=8)\end{array}$ & $\begin{array}{l}\text { conducive } \\
(\mathrm{N}=40)\end{array}$ & & & & \\
\hline Gender $[\mathrm{n}(\%)]$ & & & $0.240^{\mathrm{a}}$ & & & \\
\hline men & $1(6.3)$ & $15(93.8)$ & & 1 (ref) & & \\
\hline women & $7(21.9)$ & $25(78.1)$ & & 0.18 & $0.02-2.08$ & 0.172 \\
\hline Age [years] $(\mathrm{M} \pm \mathrm{SD})$ & $30.4 \pm 7.2$ & $40.7 \pm 11.1$ & $0.016^{\mathrm{b}}$ & 1.14 & $1.01-1.27$ & 0.027 \\
\hline Employment status [n (\%)] & & & $0.428^{\mathrm{a}}$ & & & \\
\hline employed & $4(12.9)$ & $27(87.1)$ & & 1 (ref) & & \\
\hline non-employed & $4(23.5)$ & $13(76.5)$ & & 0.58 & $0.09-3.64$ & 0.561 \\
\hline Occupational classification [n (\%)] & & & $0.406^{\mathrm{a}}$ & & & \\
\hline non-managers & $7(21.2)$ & $26(78.8)$ & & 1 (ref) & & \\
\hline managers & $1(6.7)$ & $14(93.3)$ & & 5.08 & $0.41-62.91$ & 0.206 \\
\hline Education $[\mathrm{n}(\%)]$ & & & $0.999^{\mathrm{a}}$ & & & \\
\hline middle school or vocational & $1(16.7)$ & $5(83.3)$ & & 1 (ref) & & \\
\hline high school or university & $7(16.7)$ & $35(83.3)$ & & 2.00 & $0.13-30.51$ & 0.618 \\
\hline Disease $[\mathrm{n}(\%)]$ & & & $0.867^{\mathrm{a}}$ & & & \\
\hline less hindering & $2(12.5)$ & $14(87.5)$ & & 1 (ref) & & \\
\hline hindering & $5(19.2)$ & $21(80.8)$ & & 0.47 & $0.05-4.41$ & 0.505 \\
\hline very hindering & $1(16.7)$ & $5(83.3)$ & & 0.57 & 0.03-12.89 & 0.727 \\
\hline
\end{tabular}

${ }^{1}$ Odds for conducive as compared to inimical, adjusted for all other covariates listed in Table 5.

Other explanations as in Table 3.

personal covariates, an increase in age by each year increased the odds to score by $14 \%(\mathrm{OR}=1.14, \mathrm{p}=0.027)$ (Table 5). The remaining 3 dimensions were assessed as rather conducive to very conducive (Table 2) and none of the analyzed personal characteristics was found to be associated with higher scores (especially higher needs or higher demands for these) (Tables 6 and 7).

\section{DISCUSSION}

The presented investigation gave an opportunity to identify and quantify the individual opinions of PwCDs about their needs regarding the possibility to maintain or return to work after a period of withdrawal caused by an illness.
The study considered 6 domains which may determine, promote, encourage or conduce decisions about searching for a job or being employed. These domains were: workplace facilitators, unrestricted working hours, and less control and a low-stress job, legal solutions protecting PwCDs, medical support for PwCDs, access to training and counseling, and co-workers and supervisors' knowledge. In general, all the flexibility criteria and features making a workplace more facilitating were perceived as needed by the study participants.

In total, there were 39 items (areas) questioned and, among these, a high supervisor's control and the company having the right to terminate the contract were assessed 
Table 6. Subjects' characteristics associated with the perception groups identified by their attitude to medical support for PwCDs, in the Polish part of the PATHWAYS project representing persons with chronic diseases (PwCDs) in the Małopolska region, data collection in 2016-2017

\begin{tabular}{|c|c|c|c|c|c|c|}
\hline \multirow[b]{2}{*}{ Variable } & \multicolumn{2}{|c|}{ Cluster group type } & \multirow[b]{2}{*}{$\mathrm{p}$} & \multirow[b]{2}{*}{$\mathrm{OR}^{1}$} & \multirow[b]{2}{*}{$95 \% \mathrm{CI}$} & \multirow[b]{2}{*}{$\mathrm{p}$} \\
\hline & $\begin{array}{l}\text { rather conducive } \\
\qquad(\mathrm{N}=15)\end{array}$ & $\begin{array}{l}\text { very conducive } \\
\qquad(\mathrm{N}=41)\end{array}$ & & & & \\
\hline Gender $[\mathrm{n}(\%)]$ & & & $0.999^{\mathrm{a}}$ & & & \\
\hline men & $4(23.5)$ & $13(76.5)$ & & 1 (ref) & & \\
\hline women & $11(28.2)$ & $28(71.8)$ & & 0.64 & $0.14-3.03$ & 0.577 \\
\hline Age [years] $(\mathrm{M} \pm \mathrm{SD})$ & $40.7 \pm 13.7$ & $38.7 \pm 10.6$ & $0.690^{\mathrm{b}}$ & 0.99 & $0.93-1.05$ & 0.700 \\
\hline Employment status [n (\%)] & & & $0.354^{c}$ & & & \\
\hline employed & $8(22.2)$ & $28(77.8)$ & & 1 (ref) & & \\
\hline non-employed & $7(35.0)$ & $13(65.0)$ & & 0.44 & $0.11-1.67$ & 0.226 \\
\hline Occupational classification [n (\%)] & & & $0.321^{\mathrm{a}}$ & & & \\
\hline non-managers & $9(22.5)$ & $31(77.5)$ & & 1 (ref) & & \\
\hline managers & $6(37.5)$ & $10(62.5)$ & & 0.58 & $0.14-2.39$ & 0.454 \\
\hline Education [n (\%)] & & & $0.999^{\mathrm{a}}$ & & & \\
\hline middle school or vocational & $1(16.7)$ & $5(83.3)$ & & 1 (ref) & & \\
\hline high school or university & $14(28.0)$ & $36(72.0)$ & & 0.49 & $0.05-5.26$ & 0.554 \\
\hline Disease $[\mathrm{n}(\%)]$ & & & $0.190^{\mathrm{a}}$ & & & \\
\hline less hindering & $8(42.1)$ & $11(57.9)$ & & 1 (ref) & & \\
\hline hindering & $6(21.4)$ & $22(78.6)$ & & 3.22 & $0.78-13.32$ & 0.107 \\
\hline very hindering & $1(11.1)$ & $8(88.9)$ & & 6.58 & $0.59-72.98$ & 0.125 \\
\hline
\end{tabular}

Ref - reference.

${ }^{1}$ Odds for very conducive as compared to rather conducive, adjusted for all other covariates listed in Table 6 .

${ }^{a}$ Fisher's exact test; ${ }^{\mathrm{b}}$ Mann-Whitney $\mathrm{U}$ test; ${ }^{\mathrm{c}}$ Chi-square test with 1 degree of freedom.

as inimical in maintaining or returning to work. The items such as having a low-risk job, solutions which enable PwCDs to do some higher-risk jobs on special conditions, and a low supervisor's control received mean scores which may be interpreted as somehow needed - they were slightly above the opinions meaning "neither conducive nor inimical" in the direction of "conducive." All the other possible workplace or job-related facilitators were scored as needed (expressed as "conducive" and "very conducive"). Although every flexibility and facilitator may be conducive for PwCDs to maintain or return to work, this study gave an opportunity to identify those persons for whom some issues are perceived as more important and more needed. In this research, the PwCDs with high school or university education expressed stronger needs to have access to workplace facilitators and unrestricted working hours with a low-stress job. Age was associated with higher needs for legal solutions, a hindering type of the disease (but not very hindering), and higher needs for workplace facilitators. Being non-employed, however, was found to decrease the odds to express higher needs for a facilitating workplace.

The level of needs quantification, as expressed by PwCDs, depends on several personal factors. Individual perception 
Table 7. Subjects' characteristics associated with the perception groups identified by their attitude to access to training and counseling, in the Polish part of the PATHWAYS project representing persons with chronic diseases (PwCDs) in the Małopolska region, data collection in 2016-2017

\begin{tabular}{|c|c|c|c|c|c|c|}
\hline \multirow[b]{2}{*}{ Variable } & \multicolumn{2}{|c|}{ Cluster group type } & \multirow[b]{2}{*}{$\mathrm{p}$} & \multirow[b]{2}{*}{$\mathrm{OR}^{1}$} & \multirow[b]{2}{*}{$95 \% \mathrm{CI}$} & \multirow[b]{2}{*}{$\mathrm{p}$} \\
\hline & $\begin{array}{l}\text { conducive } \\
(\mathrm{N}=22)\end{array}$ & $\begin{array}{l}\text { very conducive } \\
\quad(\mathrm{N}=34)\end{array}$ & & & & \\
\hline Gender $[\mathrm{n}(\%)]$ & & & $0.772^{\mathrm{a}}$ & & & \\
\hline men & $6(35.3)$ & $11(64.7)$ & & 1 (ref) & & \\
\hline women & $16(41.0)$ & $23(59.0)$ & & 0.40 & $0.09-1.72$ & 0.218 \\
\hline Age [years] $(\mathrm{M} \pm \mathrm{SD})$ & $41.5 \pm 12.1$ & $37.7 \pm 10.9$ & $0.275^{\mathrm{b}}$ & 0.97 & $0.92-1.02$ & 0.244 \\
\hline Employment status [n (\%)] & & & $0.394^{\mathrm{a}}$ & & & \\
\hline employed & $16(44.4)$ & $20(55.6)$ & & 1 (ref) & & \\
\hline non-employed & $6(30.0)$ & $14(70.0)$ & & 1.87 & $0.54-6.56$ & 0.326 \\
\hline Occupational classification [n (\%)] & & & $0.765^{\mathrm{a}}$ & & & \\
\hline non-managers & $15(37.5)$ & $25(62.5)$ & & 1 (ref) & & \\
\hline managers & $7(43.8)$ & $9(56.3)$ & & 0.96 & $0.26-3.60$ & 0.957 \\
\hline Education $[\mathrm{n}(\%)]$ & & & $0.670^{\mathrm{a}}$ & & & \\
\hline middle school or vocational & $3(50.0)$ & $3(50.0)$ & & 1 (ref) & & \\
\hline high school or university & $19(38.0)$ & $31(62.0)$ & & 2.42 & $0.34-17.30$ & 0.377 \\
\hline Disease $[\mathrm{n}(\%)]$ & & & $0.348^{c}$ & & & \\
\hline less hindering & $10(52.6)$ & $9(47.4)$ & & 1 (ref) & & \\
\hline hindering & $9(32.1)$ & $19(67.9)$ & & 2.88 & $0.75-11.03$ & 0.123 \\
\hline very hindering & $3(33.3)$ & $6(66.7)$ & & 2.06 & $0.33-12.73$ & 0.438 \\
\hline
\end{tabular}

Ref - reference.

${ }^{a}$ Chi ${ }^{2}$ test with 1 degree of freedom; ${ }^{b}$ Mann-Whitney U test; ${ }^{\mathrm{c}}$ Fisher's exact test.

${ }^{1}$ Odds for very conducive as compared to conducive, adjusted for all other covariates listed in Table 7.

of benefits, increased job satisfaction, positive experiences, the knowledge about possible adjustments, and an internal drive are among the most important [22]. The needs of PwCDs are frequently assessed in literature from the negative points of view, as these persons frequently experience exclusion and stigma [23]. This is typically observed among people with mental health problems, among whom these factors are among the causes of withdrawal from the labor market [24]. In consequence, the potential solutions to this problem include interventions to improve work participation of PwCDs, which focus on encouragement and empowerment, and which include behavioral counseling and psychological interventions to reduce fatigue, to develop problem-solving skills, and to develop the appropriate and effective coping strategies [25]. In this research, education was recognized as a factor associated with higher demands. The educational level may impose the perception of needs in several ways. Education is a good marker of a general capacity and ability to manage difficult situations, and is closely linked to social gradients, which are associated with multiple barriers in returning to work, such as low(er) skills, higher local unemployment rates or employer discrimination. It was also shown that education is among the successful interventions to enhance work par- 
ticipation of PwCDs [26,27]. The higher needs for workplace facilitators which were reported by the PwCDs involved in this research are consistent with the intervention studies showing an increase in the prospects of returning to work by reducing barriers, changes to the workplace or equipment, changes in the work design and organization, and changes in working conditions or work environment [28].

The share of PwCDs who are outside the labor market in Poland is relatively high, and higher than in other EU countries. Among disabled persons in Poland, only about $14 \%$ were hired in 2016 (at the registered unemployment rate in 2016 of $6.2 \%$ ). According to the Health Status of Population in Poland in 2014 survey, disabled persons had, in general, lower educational levels (a higher share of people with middle school [31\%] or vocational [30\%] education than the general population) [29]. The current situation is probably the consequence of changes which took place in the 21st century in Poland, which placed PwCDs in a difficult reality, with a restricted access to facilitating workplaces, and very limited opportunities to express their needs and expectations. Additionally, due to the occupational rehabilitation changes which occurred after the period of economic transition (as described in Introduction), there is currently no special interest on the part of employers in Poland to invest in and develop adjustments and workplace facilitators for PwCDs. Subsidies from the State Fund for Rehabilitation of Disabled People (Państwowy Fundusz Rehabilitacji Osób Niepełnosprawnych - PFRON) are too low (from PLN 450, approximately EUR 100, for a worker with a slight degree of disability, to PLN 2400, approximately EUR 550, for a worker with a significant degree of disability, diagnosed with "special disease," i.e., with a mental impairment, a psychological disease, a moderate or severe vision disorder or epilepsy) to mobilize or encourage managers to employ disabled persons, and they are allowed only to those who have a disability certificate [30]. The results obtained by the authors, although based on a small sample size, may have some practical applications.
Firstly, they have shown that PwCDs attach importance to workplace facilitators. The adaptation of the workplace usually requires some investments. In Poland, there is a possibility to reimburse these by PFRON, provided that the company receives a positive opinion from the National Labor Inspectorate and the disabled person is hired for at least 36 months; otherwise, the company has to give back a part of the reimbursement. Therefore, companies, especially private, are not willing to take that chance. The simplification of the whole process, and some non-repayable subsidies or tax relieves might improve this situation.

Secondly, the study participants highlighted the demand for unrestricted working hours and some other legal solutions, which calls for the need of developing some legal solutions to set flexible working hours and possibilities to work from home.

Thirdly, PwCDs wished to have a low-stress job, which shows an importance of psychological interventions and effective coping skills. Therefore, there should be more investments in social security and occupational rehabilitation systems to make these services easily available. In this respect, one of the strengths of the presented study is the knowledge of the needs of PwCDs, which seems to be the key element required for public health and labor market decision-makers, economists and politicians. In making successful workplace accommodations, the type of adaptations (what should be done and in which area) depends largely on the perception of PwCDs. Once implemented, these may help the currently working PwCDs to improve their job satisfaction and productivity, and encourage those who are staying outside the labor market to return. This study provides some evidence that all these elements are actually important to PwCDs.

In addition, the study enabled the authors to quantitatively assess the needs of PwCDs related to maintaining or returning to work, and identified some personal characteristics which are associated with higher demands in some areas. This study, however, is not free from limitations. The small sample size limited an in-depth analysis 
regarding the detailed characteristics of those people who are linked to special workplace preferences and needs. It would be worth knowing the limitation and disability levels linked with different demands, and also the occupation of these persons. The small sample size led to a lower estimation precision in the analyses. It was, therefore, hard to draw a definite conclusion on the size of the impact of investigated factors on the actual level of needs. There is also a set of possible covariates which were not considered in this study, such as previous work experience, or whether the respondents were actively searching for a job or not.

\section{CONCLUSIONS}

In summary, PwCDs facing different disabilities experience several limitations on the labor market. They report several facilitators which are needed to maintain or return to work, but these are not provided in Poland, which leads to a high unemployment rate in this group. There is a need for the effective policy development which takes into consideration the needs of PwCDs, and the enhancement of employers' involvement.

\section{ACKNOWLEDGMENTS}

The authors would thank to the whole Consortium of the PATHWAYS project.

\section{REFERENCES}

1. Barnett K, Mercer SW, Norbury M, Watt G, Wyke S, Guthrie B. Epidemiology of multimorbidity and implications for health care, research, and medical education: a cross-sectional study. Lancet. 2012;380(9836):37-43, https://doi.org/10.1016/ S0140-6736(12)60240-2.

2. Feigl AB, Goryakin Y, Devaux M, Lerouge A, Vuik S, Cecchini M. The short-term effect of BMI, alcohol use, and related chronic conditions on labour market outcomes: A time-lag panel analysis utilizing European SHARE dataset. PLoS ONE. 2019;14(3):e0211940, https://doi.org/10.1371/ journal.pone.0211940.
3. Central Statistical Office [Internet]. Warsaw: The Office; 2018 [cited 2019 Jun 13]. [Social Surveys Department. Health care in households in 2016]. Available from: https:// stat.gov.pl/en/topics/health/health/health-care-in-households-in-2016,2,4.html. Polish.

4. Central Statistical Office [Internet]. Warsaw: The Office; 2019 [cited 2019 Jun 15]. [Labour Market Department. Labour force in Poland IV quarter 2018]. Available from: https://stat.gov.pl/en/topics/labour-market/working-unemployed-economically-inactive-by-lfs/labour-force-survey-inpoland-iv-quarter-2018,2,32.html. Polish.

5. Knoche K, Sochert R, Houston K. Promoting healthy work for workers with chronic illness: A guide to good practice [Internet]. Edinburgh: European Network for Workplace Health Promotion (ENWHP); 2012 [cited 2019 Jun 12]. Available from: http://www.imp.lodz.pl/upload/english/english/promoting\%20healthy\%20work.pdf.

6. Bartley M, Sacker A, Schoon I, Kelly MP, Carmona C. Work, non-work, job satisfaction and psychological health [Internet]. Sheffield: National Health Service Health Development Agency; 2005 [cited 2019 Jun 12]. Available from: https:// www.ucl.ac.uk/capabilityandresilience/worknonwork.pdf.

7. Black C. Work, health and wellbeing. Saf Health Work. 2012;3(4):241-2, https://doi.org/10.5491/SHAW.2012.3.4.241.

8. Madsen KP, Cleal B, Olesen K, Hagelund L, Willaing I. Willingness to pay for flexibility at the workplace for people with diabetes and chronic disease: a discrete choice experiment in a population of workers in Denmark. BMC Public Health. 2019;19(1):584, https://doi.org/10.1186/s12889-019-6919-6.

9. Peters SE, Johnston V, Ross M, Coppieters MW. Expert consensus on facilitators and barriers to return-to-work following surgery for non-traumatic upper extremity conditions: a Delphi study. J Hand Surg Eur. 2017;42(2):127-36, https:// doi.org/10.1177/1753193416669263.

10. Hayman JR. Flexible work arrangements: exploring the linkages between perceived usability of flexible work schedules and work/life balance. Community Work Family. 2009;12(3): 327-38, https://doi.org/10.1080/13668800902966331. 
11. Czuba KJ, Kayes NM, McPherson KM. Support workers' experiences of work stress in long-term care settings: a qualitative study. Int J Qual Stud Health Well-being. 2019;14(1):1622356, https://doi.org/10.1080/17482631.2019.1622356.

12. Hulek A. [Science in serving disable people]. In: Mikulski J, editor. [Rehabilitation of the disabled as a social service TWK: 1960-2005], Warsaw: Polskie Towarzystwo Walki z Kalectwem; 2004. p. 55-64. Polish.

13. Kirenko J. [Psychophysical and social functioning possibilities among persons with mental impairment]. In: Mikulski J, editor. [Rehabilitation of the disabled as a social service TWK: 1960-2005], Warsaw: Polskie Towarzystwo Walki z Kalectwem; 2004. p. 172-95. Polish.

14. Sokołowska M, editor. [The situation of disabled people and the state of rehabilitation of the PRL. Expertise]. Wrockaw: Zakład Narodowy im. Ossolińskich; 1984. Polish.

15. Majewski T. [Development of occupational rehabilitation of disabled people in Poland 1990]. Warsaw: TWK; 2011. Polish.

16. [Regulation of the Council of Ministers of May 5, 1968 regarding planned employment of disabled. J Laws 1968, item 88]. Polish.

17. Cioch H. [The influence of cooperative law on the development of cooperatives after 1989]. Biulet Instytutu Stefczyka. 2010;(5):46. Polish.

18. [Act of 20 January 1990 on changes in the organization and operation of cooperatives. J Laws 1990, item 56]. Polish.

19. Waszkowski H. [The disabled cooperative movement and its meaning for the development of the rehabilitation of disabled people in Poland]. Disability - Issues, Problems, Solutions. 2016;4(21):97-122. Polish.

20. Leonardi M, Scaratti C. Employment and People with Non Communicable Chronic Diseases: PATHWAYS Recommendations and Suggested Actions for Implementing an Inclusive Labour Market for All and Health in All Sectors. Int J Environ Res Public Health. 2018;15(8):1674, https://doi. org/10.3390/ijerph15081674.

21. Piłat A, Woźniak B, Tobiasz-Adamczyk B, Brzyska M, Leonardi M, Ferraina S, et al. Difficult entry and return to the labor market: on the professional (re)integration of people with disabilities and chronic health conditions in Poland (The PATHWAYS research project). Int J Occup Med Environ Health. 2019;32(4):475-88, https://doi.org/10.13075/ ijomeh.1896.01352.

22. Faragher EB, Cass M, Cooper CL. The relationship between job satisfaction and health: a meta-analysis. Occup Environ Med. 2005;62(2):105-12, https://doi.org/10.1136/ oem.2002.006734.

23. Sveinsdottir V, Eriksen HR, Baste V, Hetland J, Reme SE. Young adults at risk of early work disability: who are they? BMC Public Health. 2018;18(1):1176, https://doi.org/10. 1186/s12889-018-6095-0.

24. Merz MA, Bricout JC, Koch LC. Disability and job stress: Implications for vocational rehabilitation planning. Work. 2001;17(2):85-95.

25. Finnes A, Enebrink P, Ghaderi A, Dahl J, Nager A, Öst LG. Psychological treatments for return to work in individuals on sickness absence due to common mental disorders or musculoskeletal disorders: a systematic review and meta-analysis of randomized-controlled trials. Int Arch Occup Environ Health. 2019;92(3):273-93, https://doi.org/10.1007/s00420018-1380-x.

26. Foitzek N, Ávila CC, Ivandic I, Bitenc Č, Cabello M, Gruber S, et al. What Persons with Chronic Health Conditions Need to Maintain or Return to Work-Results of an Online-Survey in Seven European Countries. Int J Environ Res Public Health. 2018;15(4):595, https://doi.org/10.3390/ijerph15040595.

27. Vooijs M, Leensen MCJ, Hoving JL, Wind H, Frings-Dresen $\mathrm{MH}$. Interventions to enhance work participation of workers with a chronic disease: a systematic review of reviews. Occup Environ Med. 2015;72(11):820-6, https://doi. org/10.1136/oemed-2015-103062.

28. Van Oostrom SH, Driessen MT, de Vet HCW, Franche RL, Schonstein E, Loisel P, et al. Workplace interventions for preventing work disability. Cochrane Database of Systematic Reviews. 2009;2:CD006955,https://doi.org/10.1002/14651858. CD006955.pub2. 
29. Central Statistical Office [Internet]. Warsaw: The Office; 2016 [cited 2019 Jun 13]. [Social Surveys and Living Conditions Department. Health Status of Population in Poland in 2014]. Available from: https://stat.gov.pl/en/topics/health/ health/health-status-of-population-in-poland-in-2014,4,1. html. Polish.
30. State Fund for Rehabilitation of Disabled People [Internet]. Warsaw: The Fund; 2019 [cited 2019 Jun 12]. Funding amounts. Available from: https:/www.pfron.org.pl/en/employers/remuneration-funding/funding-amount/.

This work is available in Open Access model and licensed under a Creative Commons Attribution-NonCommercial 3.0 Poland License - http://creativecommons.org/ licenses/by-nc/3.0/pl/deed.en. 